\title{
Comentario
}

\section{Camino hacia la teoría bibliotecológica}

$\prod_{\text {heorein es el verbo griego de donde derivó la palabra theo- }}^{\text {ria de hondas resonancias para el desarrollo del conoci- }}$ miento. Este verbo significa la acción inmediata de ver u observar, pero al ser entendido como un movimiento mental se transfiguró en un acto de contemplación. Transfiguración que implicó un desplazamiento fundamental que va de la percepción a la intelección, de lo concreto a lo abstracto. La teoría fue así comprendida como una actividad contemplativa y, más rigurosamente, como un proceso de especulación intelectual para conocer el universo. La palabra inventada por los griegos viene a expresar por lo mismo la nueva forma como el ser humano pasa a relacionarse con el mundo que lo rodea. Ya no es sólo una relación inmediata y empírica sino que se toma distancia para comprenderlo abstractamente, con lo que la racionalidad humana profundiza en la esencia de la realidad para dar una visión orgánica y sistemática de ella. Por ello una definición flexible de teoría, considerando la multiplicidad de definiciones que se han hecho de ella, es la que la caracteriza como un cuerpo coherente de conocimientos sobre un dominio de objetos. A lo que se puede agregar que cuando este cuerpo de conocimientos es formalizado da lugar a una teoría axiomática. Una vez que la mente humana perfiló el camino teórico, el horizonte de los conocimientos cambio definitivamente. Pero ese camino no ha sido ni es unitario, ni de una sola dirección; por momentos se acerca estrechamente a la realidad por la vía de la práctica y en otros se aleja de ella para encerrarse en la abstracción pura, esto dependiendo de la concepción que se tenga y elabore de ella. De ahí también las ambiguas relaciones que guarda con respecto a la práctica; así, hay quienes privilegian a una sobre la otra, aspirando incluso a separarlas de forma casi completa, sin lograrlo del todo. Lo cual deja en evidencia la persistencia del 
pensamiento teórico por conservar sus nexos con la realidad, pero más aún su necesidad para llevar adelante el proceso de conocimiento. La teoría no es un lujo intelectual sino una necesidad cognoscitiva. En la fase actual de avance de los campos de conocimiento se hace insoslayable la implementación y desarrollo de la teoría a gran escala, de lo contrario se corre el riesgo del estancamiento e incluso la regresión. Los campos que han podido consolidar su estatuto científico lo han hecho porque crearon un conocimiento fundado teóricamente, que les permitió tomar distancia de un empirismo inmediato de estrechas miras que frenaba su desarrollo, para elevarse hacia un conocimiento abstracto que determina y orienta la actividad práctica sobre el dominio de los objetos que les es propio a cada uno.

Así como hay campos de conocimiento que han alcanzado su completa autonomía y marcan las pautas de desarrollo del conocimiento gracias a su fundamentación teórica, existen por el contrario otros campos que han quedado varados en su fase de constitución, caracterizada ésta por la perseverancia de una actividad cognoscitiva primordialmente empírica e inmediatista que obstruye la gestación de su propia teoría, uno de ellos es precisamente el campo bibliotecológico. Campo que al no avocarse de manera determinante y en conjunto a la construcción de su propia teoría ha limitado su gran potencial que, como bien lo comprendió Jesse Shera, consiste en ser "una gran fuerza unificadora, no sólo en el mundo del saber sino en el de toda la vida humana"; pero además eso le ha impedido alcanzar su fase de autonomía y proyectarse en pie de igualdad con los campos de conocimiento más desarrollados.

Una de las principales razones por las que el campo bibliotecológico quedó fijado a una actividad primordialmente empírica es que centralizó su atención cognoscitiva en los procesos técnicos internos de la biblioteca, de los que se ha pretendido exorcizar cualquier ingerencia teórica. Y si bien es cierto que la biblioteca es uno de los objetos principales de conocimiento de la bibliotecología, esta última es más que eso. De ahí que este objeto de conocimiento sea a la vez el que propicia los mayores obstáculos epistemológicos de la bibliotecología en la forja de su propia teoría. Obstáculo que sólo puede ser removido si se concibe a la biblioteca no sólo de manera exclusivamente empírica y técnica, sino también como un objeto de construcción 
abstracta y que se expande más allá de los muros de una biblioteca concreta. De manera análoga, con cada uno de los demás objetos específicos de la bibliotecología se ha de proceder a su elaboración abstracta; esto es, a su construcción epistemológica, lo que permitirá la conformación de teorías regionales sobre los objetos o sectores propios del campo y franqueará el camino hacia la constitución de la teoría bibliotecológica. Pero asimismo tal teoría habrá de mostrar permanentemente su validez (lo que implicaría no estatismo sino constante mutabilidad a partir de los cambios que sufren sus objetos de conocimiento) en la unidad inalienable que ha de guardar con la práctica. Unidad que se caracteriza por la determinación y orientación con que el pensamiento teórico encauza la práctica sobre la realidad propia de la bibliotecología.

Seguir el camino que conduce a forjar la teoría bibliotecológica, aparte de constituirse en la vía real que llevará al campo hacia su fase de autonomía en el aspecto particular, podrá dotarla de una identidad propia y definitoria para que no busque mimetizarse con ciencias ajenas a sí misma. Perfil propio de la bibliotecología signado por la auténtica cientificidad. Así, pues, el camino está abierto y esperando.

Héctor Guillermo Alfaro López 